\title{
Simulation of Electromagnetic Fields Occurring at Intersection of Traction Networks and Multicircuit Power Lines
}

\author{
Natalia V. Buyakova ${ }^{1, *}$, Andrey V. Kryukov ${ }^{2,3}$, Dmitriy A. Seredkin ${ }^{3, *}$, and Le Van Thao ${ }^{2}$. \\ ${ }^{1}$ Angarsk State Tech-nical University, 665835, Angarsk, Russia \\ ${ }^{2}$ Irkutsk State Transport University, 664074, Irkutsk, Russia \\ ${ }^{3}$ Irkutsk National Research Technical University, 664074, Irkutsk, Russia
}

\begin{abstract}
Traction networks (TN) $25 \mathrm{kV}$ generate higher electromagnetic fields (EMF) with frequency $50 \mathrm{~Hz}$, whose strengths at a standardized height of $1.8 \mathrm{~m}$, as a rule, do not exceed the permissible norms for electrical personnel. In places where railroads routes intersect with high voltage overhead power supply lines (OPL), interference of fields, generated by the traction network and OPL, occurs. This can lead to an increase in strengths and a complication of the EMF spatial structures. The article presents simulation results performed for a complex intersection, while 25 or $2 \times 25 \mathrm{kV}$ TN is crossed by a three-circuit $110-220 \mathrm{kV}$ overhead power line at 90 degrees angle. Fazonord software application was used for simulating EMF strengths in points of traction networks and OPL intersection. Based on modeling results the following conclusions have been made: at intersection points of $1 \mathrm{x} 25 \mathrm{kV}$ traction network with a three-chain 110 - $220 \mathrm{kV}$ power transmission line, the electrical field strength does not exceed the value acceptable for electrical personnel and reaches $4.2 \mathrm{kV} / \mathrm{m}$; at the intersection with $2 \times 25 \mathrm{kV}$ traction network, this parameter decreases to $2.7 \mathrm{kV} / \mathrm{m}$; the maximum amplitude of the magnetic field at the intersection points increases slightly.
\end{abstract}

\section{Introduction}

High-voltage overhead power lines (OPL) and electrified AC $25 \mathrm{kV}$ railroads are sources of industrial frequency electro-magnetic field (EMF). Electromagnetic fields with high strength levels can generate interference causing disturbances of electrical and electronic devices' normal functioning [1-4] and result in serious accidents when operations are conducted on disconnected power supply lines or communication lines when personnel is subject to induced voltage.

$25 \mathrm{kV}$ traction networks (TN) generate higher electromagnetic fields (EMF) with frequency $50 \mathrm{~Hz}$, whose strengths at a standardized height of $1.8 \mathrm{~m}$, as a rule, do not exceed the permissible norms for electrical personnel. In places where rail-roads routes intersect with high voltage overhead power supply lines (OPL), interference of fields, generated by the traction network and OPL, occurs. This can lead to an increase in strengths and a complication of the EMF spatial structures [4].

In works [2, 15-20], a method was proposed for determining the fields of multi-wire systems, including traction net-works and power lines, based on preliminary calculation of the electrical network operating mode, which may contain mul-ti-wire lines, single-phase and three-phase transformers of various types, traction $\mathrm{AC}$ networks and moving traction loads. Fazonord software application [15] designed in Irkutsk State Transport university, combines possibilities for modes simulation in phase coordinates and simultaneous calculations of EMF strengths.

This article is a further development of ideas represented in work [16], which performs a detailed analysis of electro-magnetic field structure at a point of overhead power line and a railroad perpendicular intersection.

\section{Simulation methods}

Fazonord software application was used for simulating EMF strengths in points of traction networks and OPL intersection which was conducted in four stages:

1. The calculation of OPL traction networks in phase coordinates, the results of which were used to determine potentials and currents of all wires [15];

2. Calculation of vertical and horizontal components of electrical and magnetic fields of traction networks and OPL in their own coordinates.

3. Calculation of total EMF voltages components.

4. Calculation of strengths amplitude values $E_{\max }, H_{\max }$ with provision for possible fields elliptical polarization $[2,16]$.

\section{Simulation results}

The simulation was performed for a case of intersection of $1 \times 25$ and $2 \times 25 \mathrm{kV}$ traction networks with three-circuit $110-220 \mathrm{kV}$ OPL. Spatial location of the conductive parts is shown in fig. 1. It was assumed that AC-300

\footnotetext{
* Corresponding author: dmitriy987@mail.ru
} 
wires are mounted on OPL pylons. The diagram of OPL wires transposition is shown in fig. 2 . The length of the transposed OPL divided into three sections is assumed to equal to $100 \mathrm{~km}$. Loads on $220 \mathrm{kV}$ circuits receiving end were equal to $20+j 10$ MVA, circuits $110 \mathrm{kV}-6+\mathrm{j} 3$ MVA per phase. A power transit of $8+j 8$ MVA was transmitted via the overhead catenaries of each $2 \mathrm{~km}$ long traction network. The calculation was carried out for the intersection of the traction network with the first segment of the transposed OPL.

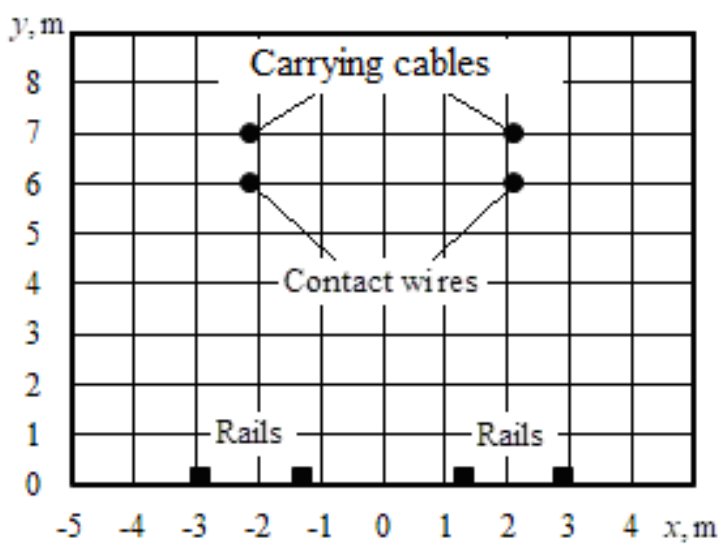

a)

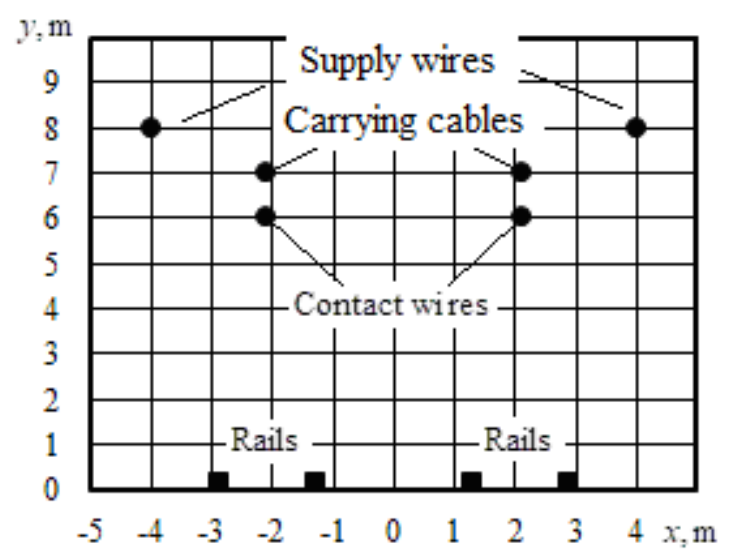

b)

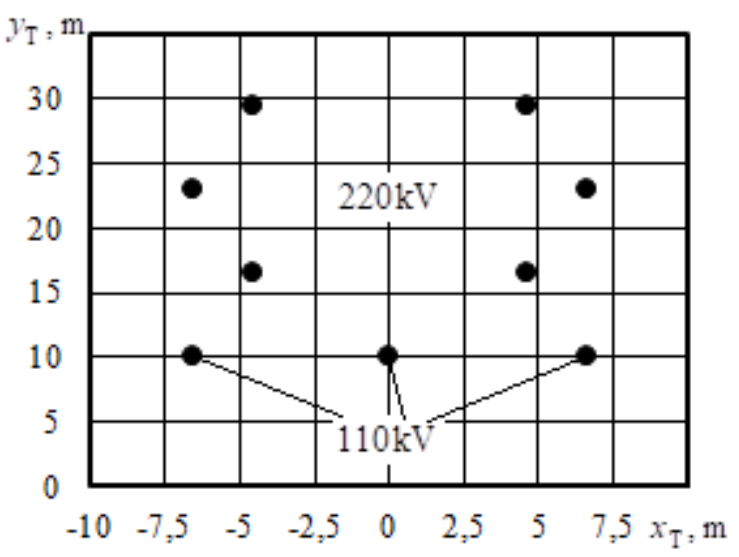

c)

Fig. 1. Wires arrangement: $\mathrm{a}-25 \mathrm{kV} \mathrm{TN} ; \mathrm{b}-2 \times 25 \mathrm{kV} \mathrm{TN}$; $\mathrm{c}-$ three-circuit OPL

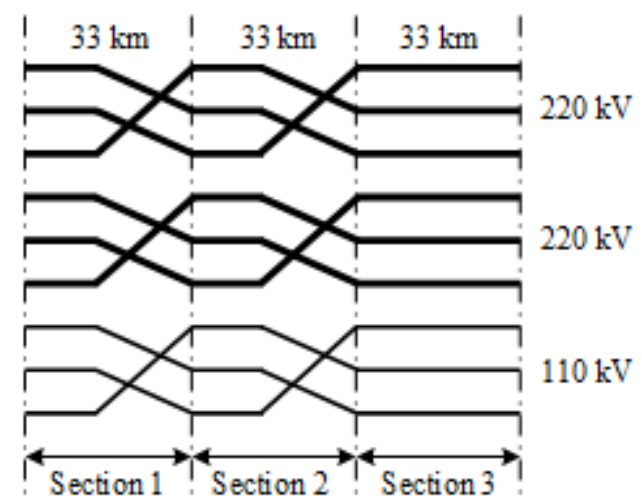

Fig. 2. OPL scheme of transposition

Table 1. Font styles for a reference to a journal article.

\begin{tabular}{|c|c|c|c|c|c|}
\hline OPL & Phase & $\begin{array}{c}U, \\
\mathrm{kV}\end{array}$ & $\begin{array}{c}U, \\
\text { degr. }\end{array}$ & $I, \mathrm{~A}$ & $I$, degr. \\
\hline \multirow{2}{*}{$\begin{array}{c}\text { Left } \\
220 \mathrm{kV}\end{array}$} & $\mathrm{A}$ & 133 & 0 & 160.6 & -18.4 \\
\cline { 2 - 6 } & $\mathrm{B}$ & 133 & -120 & 160.5 & -138.3 \\
\cline { 2 - 6 } & $\mathrm{C}$ & 133 & 120 & 160.5 & 101.7 \\
\hline \multirow{2}{*}{$220 \mathrm{kV}$} & $\mathrm{A}$ & 133 & 0 & 160.9 & -18.6 \\
\cline { 2 - 6 } & $\mathrm{B}$ & 133 & -120 & 160.9 & -138.5 \\
\cline { 2 - 6 } & $\mathrm{C}$ & 133 & 120 & 160.9 & 101.5 \\
\hline $110 \mathrm{kV}$ & $\mathrm{A}$ & 65 & 0 & 100.7 & -21.1 \\
\cline { 2 - 6 } & $\mathrm{B}$ & 65 & -120 & 100.6 & -141 \\
\cline { 2 - 6 } & $\mathrm{C}$ & 65 & 120 & 100.6 & 99.2 \\
\hline
\end{tabular}

Table 2. Voltages and currents of $1 \times 25 \mathrm{kV}$ traction network

\begin{tabular}{|c|c|c|c|c|}
\hline Path & $U, \mathrm{kV}$ & $U$, degr. & $I, \mathrm{~A}$ & $I$, degr. \\
\hline 1 & 25.6 & -5.6 & 450 & -51 \\
\hline 2 & 25.6 & -5.6 & 450 & -51 \\
\hline
\end{tabular}

Table 3. Voltages and currents of $2 \times 25 \mathrm{kV}$ traction network

\begin{tabular}{|c|c|c|c|c|c|}
\hline Path & $\begin{array}{c}\text { Place of } \\
\text { measuring }\end{array}$ & $\begin{array}{c}U, \\
\mathrm{kV}\end{array}$ & $U$, degr. & $I, \mathrm{~A}$ & $\begin{array}{c}I, \\
\text { degr. }\end{array}$ \\
\hline 1 & \multirow{2}{*}{$\begin{array}{l}\text { Overhead } \\
\text { catenary }\end{array}$} & 25.8 & 26.2 & 246.2 & -21.2 \\
\hline 2 & & 25.8 & 26.2 & 246.2 & -21.2 \\
\hline 1 & \multirow{2}{*}{$\begin{array}{l}\text { Power } \\
\text { cord }\end{array}$} & 26.5 & -153.3 & 198.7 & 164.2 \\
\hline 2 & & 26.5 & -153.3 & 198.7 & 164.2 \\
\hline
\end{tabular}

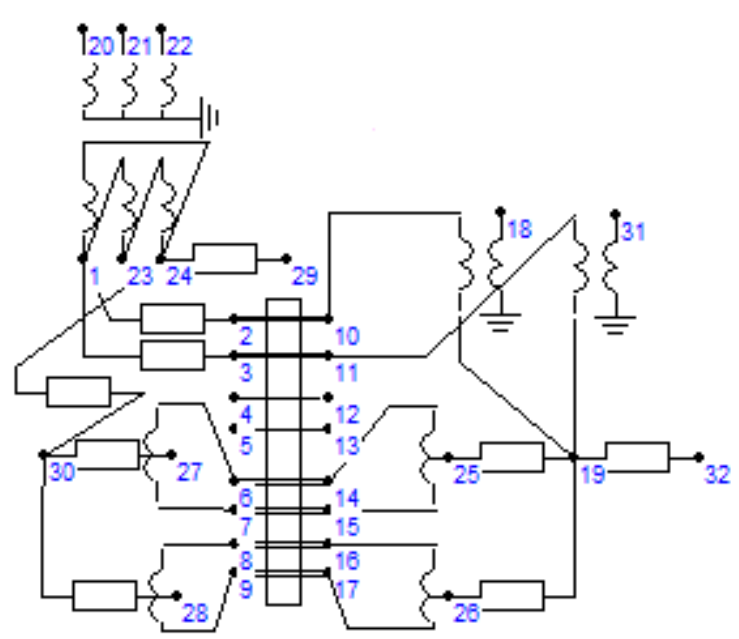

a) 


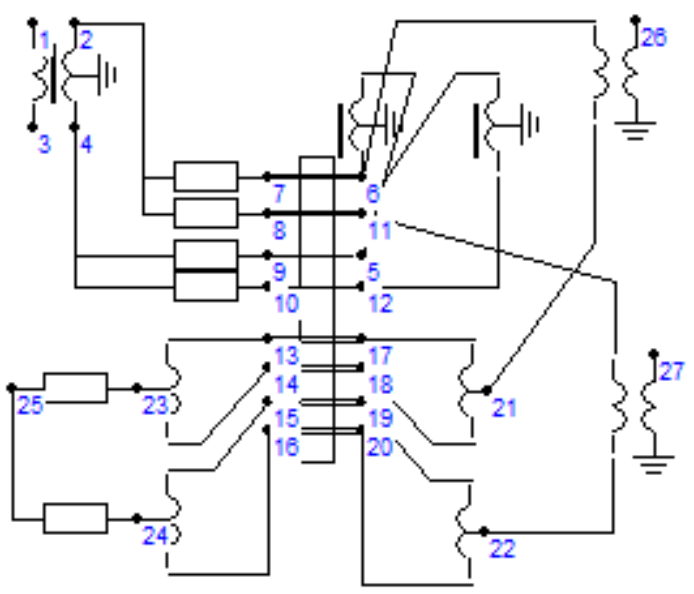

b)

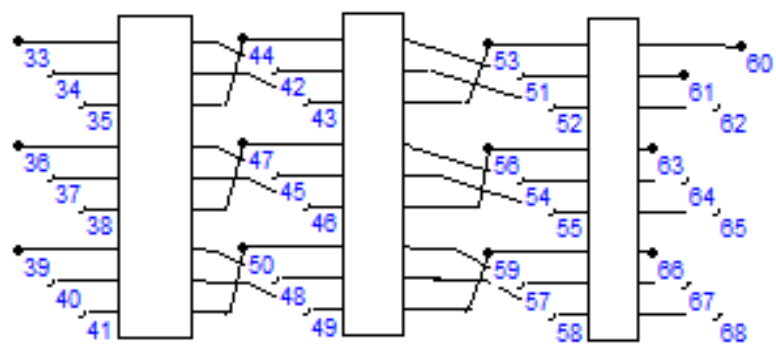

c)

Fig. 3. Fazonord PSW design models schemes: a - TC $1 \times 25 \mathrm{kV} ; \mathrm{b}-\mathrm{TC} 2 \times 25 \mathrm{kV}$; c - OPL 110-220 kV

Calculated electrical and magnetic fields strengths in their own coordinates of traction networks and OPL at a height of $1.8 \mathrm{~m}$ are provided in fig. 4-6.

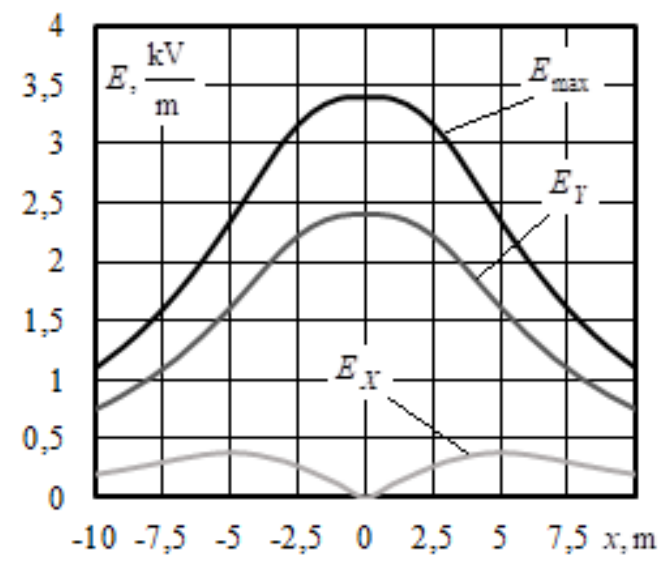

a)

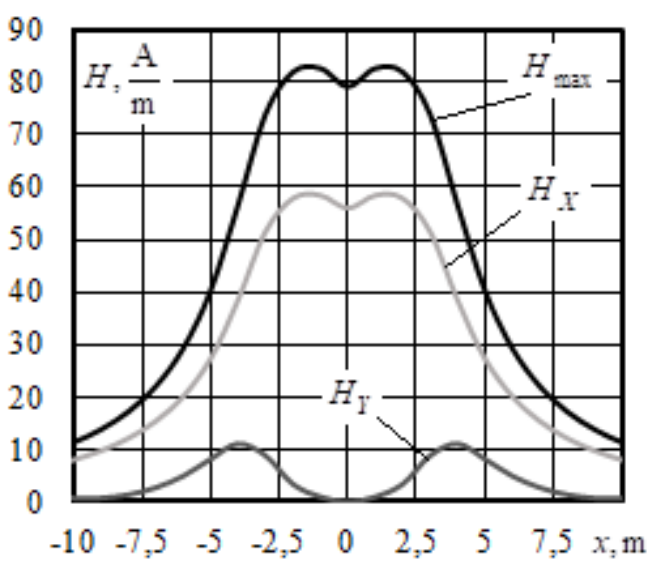

b)

Fig. 4. Electrical (a) and magnetic field (b) strengths of $25 \mathrm{kV}$ traction network at a height of $1,8 \mathrm{~m}$.

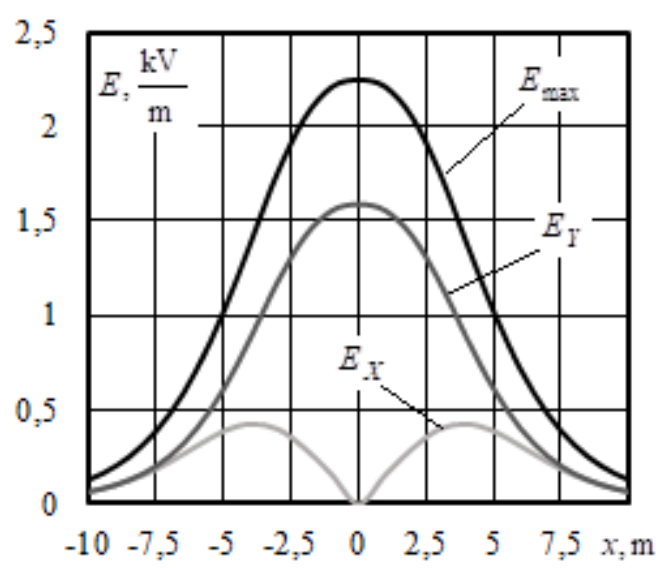

a)

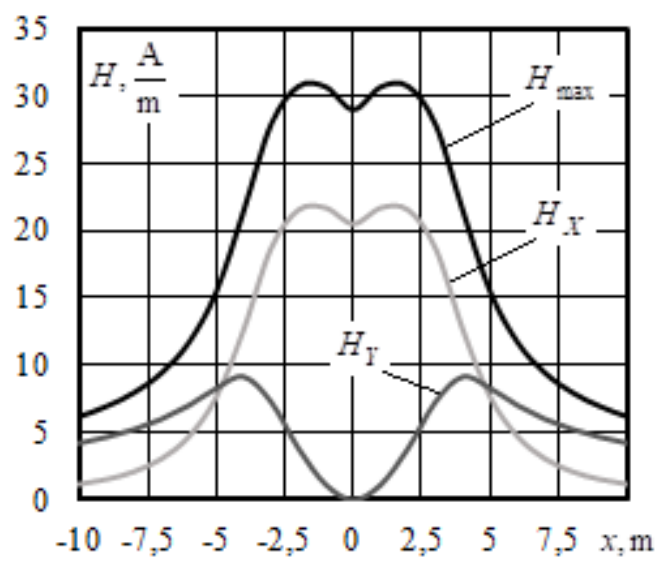

b)

Fig. 5. Electrical (a) and magnetic field (b) strengths of $2 \times 25 \mathrm{kV}$ traction network at a height of $1,8 \mathrm{~m}$. 


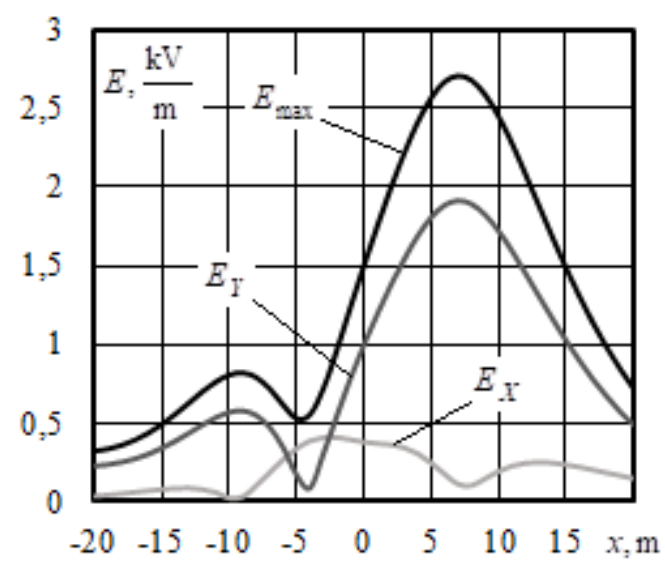

a)

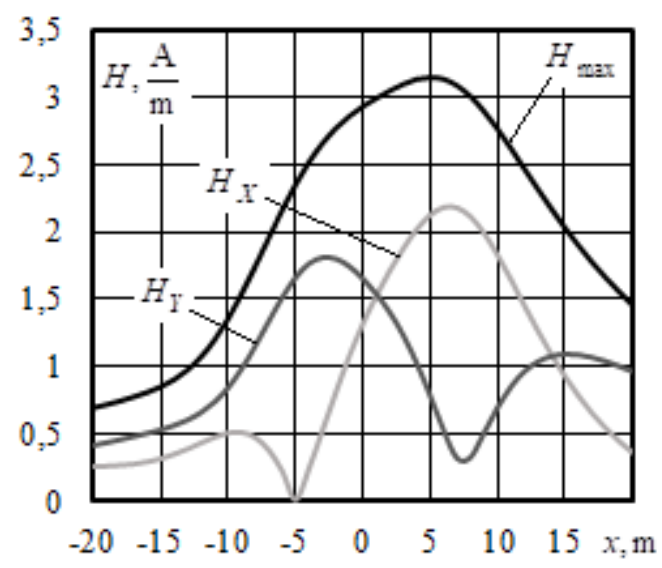

b)

Fig. 6. Electrical (a) and magnetic field (b) strengths of OPL at a height of $1,8 \mathrm{~m}$.

Volumetric diagrams of the resultant strengths of electric and magnetic fields at the intersection of traction networks and OPL at a height of $1.8 \mathrm{~m}$ are shown in Fig. 7, 8. Figure 9 shows the hodographs of the resultant strengths vectors. Table 4 represents maximal values of electrical and magnetic fields strengths at intersection points.

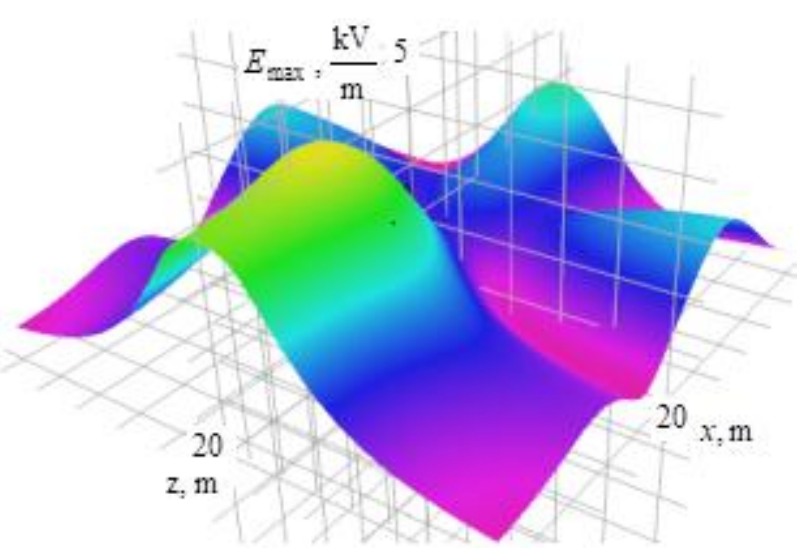

a)

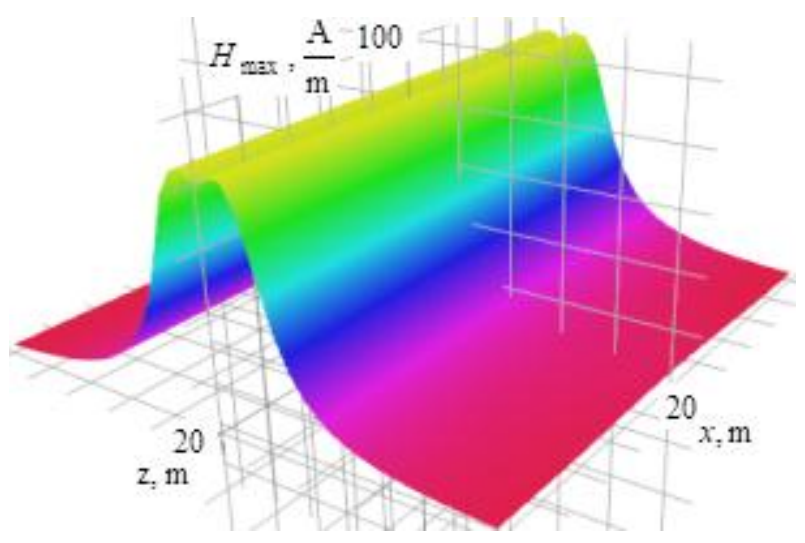

b)

Fig. 7. Amplitude values of EMF strengths at the point of $2 \times 25 \mathrm{kV}$ traction network OPL intersection: a electrical field; $\mathrm{b}$ - magnetic field

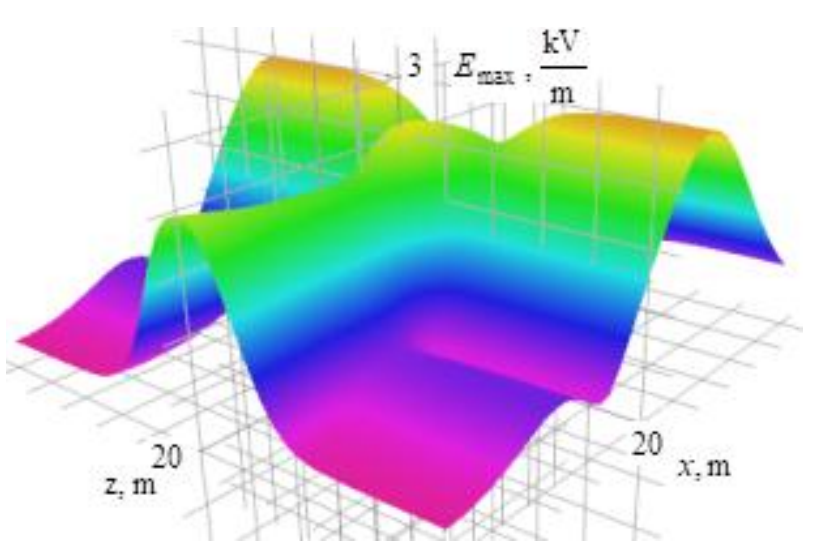

a)

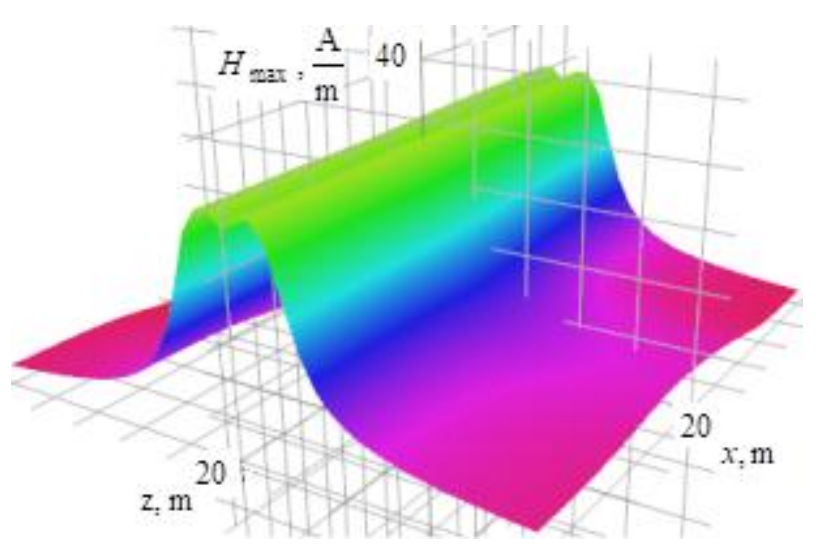

b)

Fig. 8. Amplitude values of magnetic field strengths at the point of $2 \times 25 \mathrm{kV}$ traction network and $220 \mathrm{kV}$ OPL intersection: $a$ - electrical field; $b$ - magnetic field 


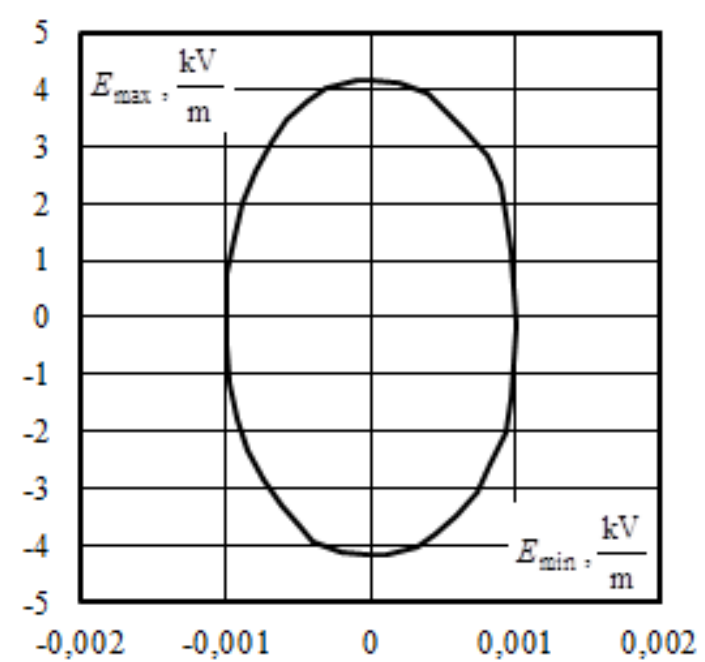

a)

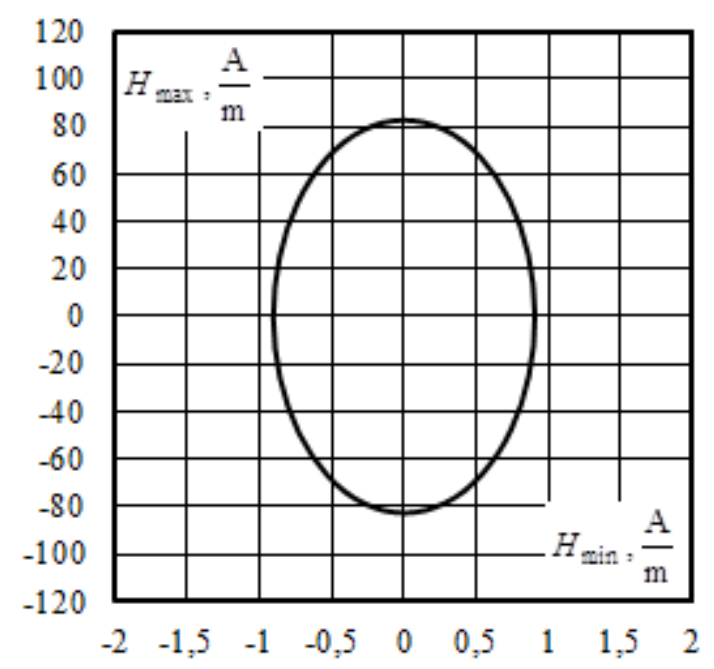

b)

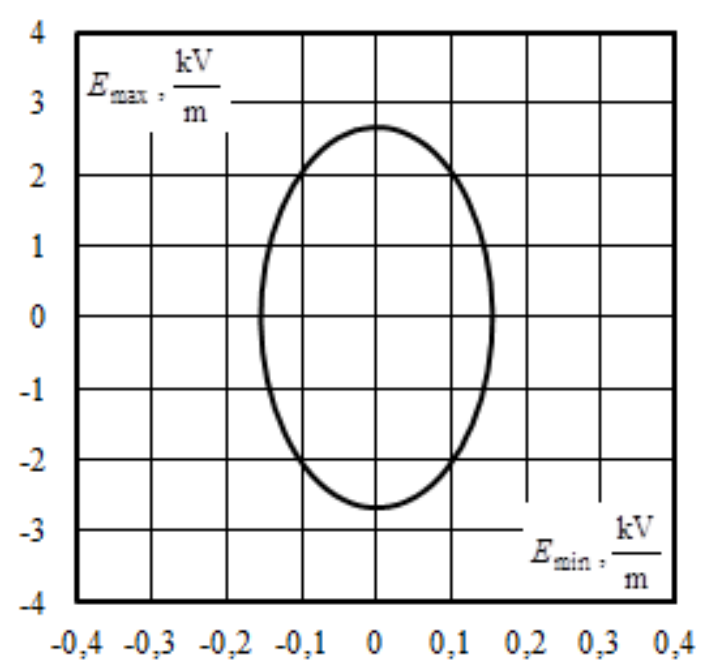

c)

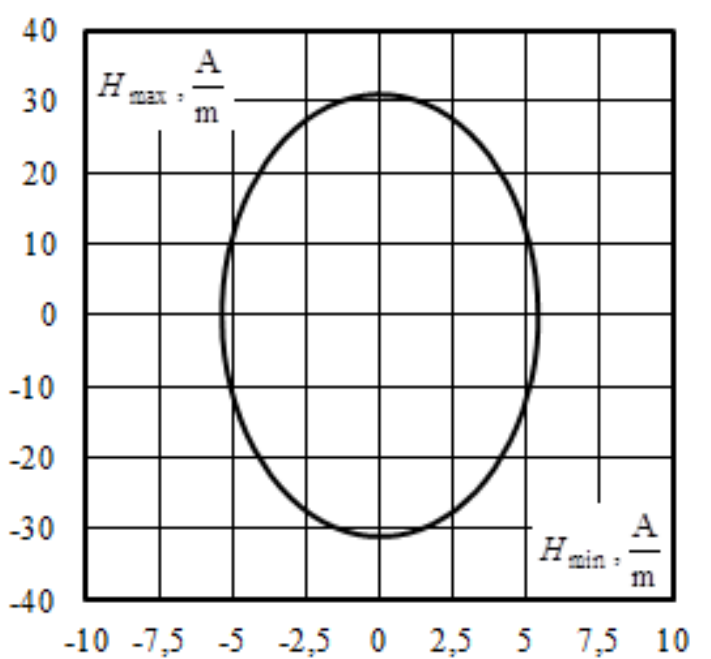

d)

Fig. 9. Hodographs of resultant vectors at points with maximal values of electrical $(\mathrm{a}, \mathrm{c})$ and magnetic $(\mathrm{b}, \mathrm{d})$ fields strengths for crossing TN $25 \mathrm{kV}(\mathrm{a}, \mathrm{b})$ and $2 \times 25$ $\mathrm{kV}(\mathrm{c}, \mathrm{d})$ with OPL: a - point $x=0 \mathrm{~m}, z=9 \mathrm{~m}$; b - point $x=1 \mathrm{~m}, z=0 \mathrm{~m} ; \mathrm{c}-$ point $x=-18 \mathrm{~m}, \mathrm{z}=-7 \mathrm{~m} ; \mathrm{d}-$ point $x=2 \mathrm{~m}, \mathrm{z}=3 \mathrm{~m}$

Table 4. Maximum values of electrical and magnetic fields strengths

\begin{tabular}{|c|c|c|c|c|c|c|c|}
\hline \multirow[b]{2}{*}{ 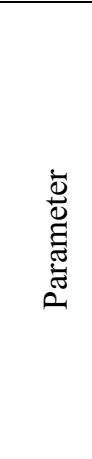 } & \multirow[b]{2}{*}{ 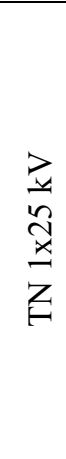 } & \multirow[b]{2}{*}{ 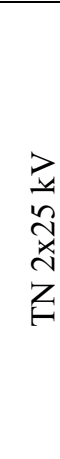 } & \multirow{2}{*}{ 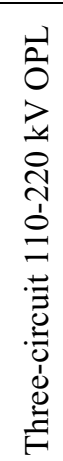 } & \multicolumn{2}{|c|}{$\begin{array}{c}\mathrm{TN} \text { and } \\
\mathrm{OPL} \\
\text { intersecti } \\
\text { on }\end{array}$} & \multicolumn{2}{|c|}{$\begin{array}{c}\text { Difference, } \\
\%\end{array}$} \\
\hline & & & & $\begin{array}{l}\frac{z}{4} \\
\stackrel{x}{x}\end{array}$ & $\frac{7}{2}$ & 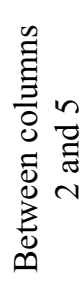 & 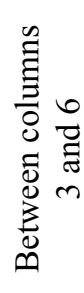 \\
\hline 1 & 2 & 3 & 4 & 5 & 6 & 8 & 9 \\
\hline $\begin{array}{l}E_{\max }, \\
\mathrm{kV} / \mathrm{m}\end{array}$ & 3,4 & 2,3 & 2,7 & 4,2 & 2,7 & 19 & 15 \\
\hline $\begin{array}{l}H_{\max }, \\
\mathrm{A} / \mathrm{m}\end{array}$ & 83 & 31 & 3,1 & 83 & 31 & 0 & 0 \\
\hline
\end{tabular}

\section{Conclusion}

Based on simulation results, the following conclusions can be made:

1. When separately modeling, the electric field strengths at a standard height of $1.8 \mathrm{~m}$, do not exceed the permissible standards of $5 \mathrm{kV} / \mathrm{m}$ for electrical personnel both for traction networks and OPL. The magnetic field strength of $1 \times 25 \mathrm{kV}$ traction network exceeds the permissible value of $80 \mathrm{~A} / \mathrm{m}$. A similar parameter for the $2 \times 25 \mathrm{kV}$ traction network is reduced to $30 \mathrm{~A} / \mathrm{m}$, which is associated with the mutual compensation of the magnetic fields generated by overhead catenaries and power wires. 
2. At the intersection points of $1 \times 25 \mathrm{kV}$ traction network with a $220 \mathrm{kV}$ three-circuit OPL, the electrical field strength does not exceed the value permissible for electrical personnel and reaches $4.2 \mathrm{kV} / \mathrm{m}$. When crossing a $2 \times 25 \mathrm{kV}$ traction network, this parameter is reduced to $2.7 \mathrm{kV} / \mathrm{m}$.

3. The magnetic field strength at the intersection of power lines with $25 \mathrm{kV}$ traction network reaches 83 $\mathrm{A} / \mathrm{m}$. For $2 \times 25 \mathrm{kV}$ TN, a similar parameter is reduced to $31 \mathrm{~A} / \mathrm{m}$.

4. At the intersection of $1 \times 25$ and $2 \times 25 \mathrm{kV}$ traction networks with OPL, the maximum amplitude of the magnetic field increases insignificantly.

\section{References}

1. A.I. Sidorov, I.S. Okrainnaya, Electromagnetic fields near ultrahigh-voltage electrical installations (Chelyabinsk, 2008)

2. N.V. Byakova, V.P. Zakaryukin, A.V. Kryukov, Electromagnetic safety in railroads power supply systems: modeling and control (Angarsk, 2018)

3. A.B. Kosarev, B.I. Kosarev, Basics of electromagnetic safety of railroad transport power supply systems (Moscow.,2008)

4. S.M. Apollonsky, T.V. Kalyada, B.E. Sindalovsky, Human life safety in electromagnetic fields (St. Petersburg, 2006)

5. S.M. Appolonsky, A.N. Gorsky, Electromagnetic fields calculations (Moscow, 2006)

6. A.A. Ustinov, Improving the efficiency of energy production and use in Siberia, 517 (2005).

7. N.B. Rubtsova, M.Sh. Misrikhanov, V.N. Sedunov, A.Yu. Tokarsky, Bulletin of Samara Research Center of RAN 5(3), 839 (2012)
8. R. Kircher, J. Klühspies, R. Palka et al, Transportation Systems and Technology 4(2), 152 (2018)

9. A. Ogunsola, A. Mariscotti, Electromagnetic Compatibility in Railways (London, 2013)

10. A. Ogunsola, U. Reggiani, L. Sandrolini, EMC'09, 567 (2009)

11. F. Sheilah, Railway Electrification Systems \& Engineering (Delhi 2012)

12. A. Steimel, Electric traction motive power and energy supply. Basics and practical experience (Munchen, 2008)

13. A.R. Zakirova, Zh.M. Bukanov, Bulletin of the Ural State University for railroads communication 2, 73 (2016)

14. A.R. Zakirova, Protection of electrical personnel against harmful effect of electromagnetic fields (Ekaterinburg, 2018)

15. V.P. Zakaryukin, A.V. Kryukov, Complex asymmetrical modes of electrical systems (Irkutsk, 2005)

16. V.P. Zakaryukin, A.V. Kryukov, Transport infrastructure of Siberian region, 641 (2018)

17. V.P. Zakaryukin, A.V. Kryukov, N.V. Buyakova, The power grid of the future, 39 (2013)

18. N. Buyakova, V. Zakarukin, A. Kryukov, Advances in Intelligent Systems Research 158, 20 (2018)

19. N. Buyakova, V. Zakaryukin, A. Kryukov, Tu Nguyen, E3S, 1 (2018)

20. N.V. Buyakova, V.P. Zakaryukin, A.V. Kryukov, Advances in Engineering Research 158, 219 (2018) 